\title{
LA INVENCIÓN DEL TOXICÓMANO COMO SUJETO A CORREGIR. \\ LA FIGURA DEL TOXICÓMANO EN LA PRODUCCIÓN DISCURSIVA FARMACÉUTICA CHILENA DE LA PRIMERA MITAD DEL SIGLO XX ${ }^{1}$
}

\author{
The invention of drug addict as subject to correct. \\ The figure of drug addict in the Chilean pharmaceutical discursive \\ production of the first half of the 20th century
}

\author{
Ricardo Camargo Brito* \\ Nicolás Ried Soto**
}

\begin{abstract}
RESUMEN
Este artículo indaga la forma en que se construye discursivamente la figura del toxicómano en la producción académica-científica de la primera mitad del siglo XX chileno. Mediante un análisis documental de las más importantes revistas farmacológicas chilenas de la época se establece que el toxicómano no existía de manera problemática, sino hasta que la difusión de un fragmentado saber farmacológico (científico, policial y político) configura la subjetividad de quienes consumían ciertos estupefacientes como un problema de salud pública a corregir. La figura del toxicómano es así mejor entendida como "sujeto a corregir", en la perspectiva de Foucault, y presenta rasgos propios de una anormalidad construida para el gobierno de poblaciones sanas, la que luego debe terminar asociado a la figura del traficante para mantener su potencial normalizador. Con ello se confirma la producción de un discurso de corrección social directamente asociado con las demandas de la generación de una vida productiva que primó en círculos académicos y políticos de comienzos de siglo en nuestro país.
\end{abstract}

Palabras clave: toxicomanía, farmacología, biopolítica, anormales, Foucault.

\footnotetext{
${ }^{1}$ Este artículo es fruto del proyecto Fondecyt Regular $\mathrm{N}^{\circ} 1170940$.

* Facultad de Derecho, Universidad de Chile. Santiago, Chile. Correo electrónico: rcamargo@ derecho.uchile.cl

*Facultad de Derecho, Universidad de Chile. Santiago, Chile.Correo electrónico: nicolasried@ gmail.com
}

Artículo recibido el 25 de octubre de 2018. Aceptado el 13 de marzo de 2019. 


\begin{abstract}
This article explores the way in which the figure of the drug addict is constructed discursively in the academic-scientific production of the first half of the 20th century in Chile. Through a documentary analysis of the most important Chilean pharmacological journals of the time it is established that the drug addict did not exist in a problematic way until the diffusion of a fragmented pharmacological knowledge (scientific, police and political) shapes the subjectivity of those who consumed certain narcotics such as a public health problem to be corrected. The figure of the addict is thus better understood as "subject to correct", in the perspective of Foucault, and presents features of an abnormality built for the government of healthy populations, which then must end associated with the figure of the trafficker to maintain its normalizing potential. This confirms the production of a discourse of social correctness directly associated with the demands of the production of a productive life that prevailed in academic and political circles of the beginning of the century in our country.
\end{abstract}

Keywords: Drug addicts, pharmacology, biopolitics, abnormals, Foucault.

\title{
1. El sujeto corregible como categoría de análisis
}

En su curso del Collège de France de 1975, publicado bajo el nombre Los anormales, Michel Foucault acuña la noción de normalización. Con ello alude a un proceso mediante el cual se gobiernan individuos a través de las disciplinas que se ejercen sobre sus cuerpos y, al mismo tiempo, se regulan las conductas de esos individuos considerados en cuanto especie y parte de una población (Castro, 2004). En este sentido, para Foucault la norma es parte del dispositivo mediante el cual un individuo es producido en todas sus dimensiones como un agente de la sociedad. Más aún, la norma no es un concepto neutral sino que es un espacio de disputa en el cual se juega el cómo y el para qué es producida cierta individualidad. Y ese es el punto central de la hipótesis que plantea en su curso Los anormales: no es que en la sociedad haya sujetos normales y sujetos anormales de manera pura, los cuales son separados en función de una regla neutral fundada en la ciencia, sino que el criterio mismo por el cual diferenciamos normales de anormales es una decisión que no viene a describir una realidad pre-normativa, sino que la constituye.

Siguiendo dicho criterio de investigación, Foucault analiza la figura 
del "sujeto a corregir". Se trata de una especie de anormal producido por las instituciones públicas y privadas, por sus discursos y por los mecanismos que implican su propia corrección. Así, el "sujeto a corregir" para Foucault cobra un valor específico como la forma en que la norma no solo viene a determinar la diferencia específica entre un normal y un anormal, sino que establece los criterios por los cuales un sujeto se convierte en un asunto a corregir por el aparato psiquiátrico y de salud pública (Vásquez, 2012).

La figura del "sujeto a corregir" o del corregible encarna una producción discursiva que no solo define los criterios de la anormalidad, como decíamos, sino que además produce las propias condiciones de lo que podríamos llamar un "problema de salud pública". Tanto para las instituciones públicas como la prisión, el orfanato, la clínica, el hospital psiquiátrico o la escuela, pero también para el aparato burocrático aunado en el poder del Estado, los sujetos corregibles son la forma en que dichas instituciones articulan su propia forma y delimitan sus facultades. El "sujeto a corregir" es aquel que, efectivamente, puede ser disciplinado por las instituciones psiquiátricas, clínicas, carcelarias o farmacológicas. Este fenómeno, para Foucault, permite estructurar una analítica del poder en función de cómo las propias instituciones, a través de sus discursos, producen los sujetos que serán el objeto de su corrección.

En función de esta hipótesis inaugurada por Michel Foucault, en este artículo nos proponemos dar contenido a dicha reflexión sobre el "sujeto a corregir", teniendo como objeto de análisis la figura del toxicómano durante la primera parte del siglo XX chileno ${ }^{2}$. El toxicómano se presenta como una figura que no era considerada problemática sino hasta que fue emergiendo discontinuamente su caracterización discursiva como anormal en los aparatos principales de circulación del saber científico farmacéutico. Dichos discursos académicos gremiales, produjeron un estatuto de la verdad que repercutió en otros planos discursivos, como son el plano político institucional y el plano económico social. Ahora bien, la manera específica en que se construye

\footnotetext{
${ }^{2}$ La literatura reciente en el resto de Latinoamérica es abundante e incluye trabajos compilados sobre la gobernabilidad del individuo (Sierra Castillo, 2010), el control social (Miranda y Girón Sierra (2009), y sobre eugenesia social (Miranda y Vallejo, 2012).
} 
discursivamente la figura del toxicómano como "sujeto a corregir" en la primera mitad del siglo XX chileno está llena de singularidades que este artículo rastrea y sistematiza mediante una revisión exhaustiva de las fuentes historiográficas, cuyos contenidos provienen principalmente de las disciplinas de la farmacéutica, la medicina, la criminalística y las ciencias jurídicas.

El presente análisis es una articulación múltiple de discursos institucionales, dispositivos, epistemologías y contextos sociales que permite revisar de manera genealógica la producción discursiva de la figura del toxicómano. Para ello, además de tener en cuenta las publicaciones académicas más influyentes de la época, los discursos políticos más divulgados y las tecnologías de producción características del período analizado, se revisaron las revistas sobre teoría y práctica farmacéutica más relevantes del período, cuya influencia en el quehacer de boticarios, dueños de droguerías y farmacéuticos fue fundamental. Estas revistas son:

a) Revista Farmacéutica Chilena que fue creada en 1892 por la Sociedad Farmacéutica de Santiago, para luego, en 1902, ser reeditada por la nueva Sociedad Farmacéutica Nacional. Fue una publicación mensual dirigida a los farmacéuticos, dueños de boticas y droguerías. La revista buscaba hacer circular el conocimiento de las ciencias farmacéuticas del país y velar por los intereses del gremio farmacéutico. Su contenido se basa en la publicación de investigaciones, estudios analíticos y fórmulas de medicamentos, incluyendo recomendaciones a los legisladores para la creación/derogación de normas que regulen la práctica y enseñanza farmacéutica. Esta revista se desarrolla en el contexto de profesionalización de la práctica farmacéutica en Chile, la creación de la Escuela de Farmacia de la Universidad de Chile y la confección de normas que regulen su campo de acción.

b) La Farmacia Nacional, es una publicación mensual, a cargo del editor y propietario Narciso Espinosa. Su contenido gira en torno a las características, procedimientos químicos y usos de las plantas medicinales a nivel médico. Sus editoriales, en 
la mayoría de los casos, hacen referencia a hechos históricos y políticos vinculados a la historiografía del país. En algunas ediciones sus editoriales tratan temas que atañen al gremio de los farmacéuticos, boticas y droguerías, principalmente vinculados a la creación, por parte del gobierno de turno, de normativas para el control de su actividad económica-productiva y académica.

c) Boletín Farmacéutico (1927 - 1931) nace de la Asociación Farmacéutica de Chile, siendo su finalidad procurar el desarrollo científico del país, velar por su prestigio y defender las prerrogativas de la asociación y sus socios. Sus publicaciones van desde estudios científicos, fórmulas químicas, secciones de cartas y preguntas, tesis, hasta las actas de reunión de la asociación. Fue impreso primero en Valparaíso y luego en Santiago.

d) La Farmacia Chilena (1927 - 1955), fue una publicación mensual, independiente, científica y comercial, que busca proporcionar a sus lectores todo aquello que tienda a ser útil para el farmacéutico, el práctico, el patrón, al empleado y al estudiante de farmacia. Cuenta con la ayuda del Gobierno y la Dirección de Sanidad. Sus publicaciones son generalmente trabajos científicos, prácticos, legislativos, reglamentarios, tópicos de actualidad farmacéutica y de interés común. Su fin último era ayudar a elaborar el engrandecimiento y progreso de la farmacia nacional.

e) Finalmente, la Revista de Criminología y Policía Científica que era una publicación mensual del Órgano oficial de la dirección de investigaciones, identificación y pasaportes. El Director de la revista es el Director Nacional de turno del organismo. Sus publicaciones, a diferencia de las otras fuentes consultadas, son de carácter multidisciplinar, toda vez que sus escritos provienen de diversas esferas como la policial, la médica y la científica, entre otras. Generalmente el contenido de sus editoriales versan 
sobre temáticas político-sociales desde una perspectiva mundial y nacional.

La Revista Farmacéutica Chilena y La Farmacia Chilena fueron publicaciones de carácter nacional dirigidas a farmacéuticos, dueños de boticas y droguerías, a fin de informarles de las más recientes discusiones sobre los asuntos bioquímicos conflictivos en el país y el mundo. En este sentido, lo que hacen estas revistas es tener un impacto doble que les otorga una relevancia particular. Por una parte, porque sirve a fin de construir un discurso que dará forma a una "episteme", es decir un modo de conocer y de producir conocimiento que delimite aquello que un boticario puede hacer o puede no hacer; y, por otra parte, estas revistas a la larga darán forma a las normas legales que regulan el uso de drogas y estupefacientes en el país, pero -más importante aún- impulsarán los códigos éticos de comportamiento por los que se regirán los colegios de farmacéuticos y químicos a cargo de farmacias.

Por tanto, analizar la producción discursiva presente en estas revistas es fundamental a fin de conocer las formas de producción del saber científico a nivel de las instituciones que acumulan, discuten y distribuyen el conocimiento farmacológico en el Chile de la primera mitad del siglo XX. Principalmente, porque mientras el control y la dosificación de sustancias utilizadas para el uso recreativo quedaba a criterio de los boticarios mientras no existiera una regulación formal, dicho criterio era formado por los discursos de las instituciones a las que boticarios y dueños de droguerías pertenecían, tales como el Gremio de Boticarios y Farmacéuticos de Chile o lo que luego sería la Facultad de Ciencias Químicas y Farmacéuticas de la Universidad de Chile. Y, por otra parte, luego que se publicara el Código de Moral Farmacéutica hacia los años 1930, el impacto del discurso promovido por estas revistas -que será revisado en detalle en lo que sigue- será fundamental tanto en un nivel académico como en un nivel práctico, ya que configurará los límites de lo que conoceremos como "toxicómano" no solo respecto de las clases sociales altas, sino que del resto de la población, dado que se comienza a articular un discurso científico, académico y político que se asume que amenazará a toda la 
población chilena. Ese impacto generalizado se evidenciará en la forma y los límites de las leyes promulgadas durante la segunda mitad del siglo XX, pero también -y eso es la tesis que se trabajará en este artículo- en cómo el sujeto a corregir del "toxicómano" se convertirá luego en el sujeto a disciplinar del "traficante criminal" de las leyes penales.

\section{La figura del toxicómano en Chile durante la primera mitad del siglo XX}

Chile a fines del siglo XIX y principios del siglo XX se encontraba inserto en un debate nacional acerca del problema de las condiciones de vida de los habitantes, la desigualdad entre clases sociales, el trabajo de los obreros y el futuro del país, el que se conoció como la "cuestión social". Para el diputado y luego senador conservador Enrique Concha Subercaseaux, la "cuestión social" refería a problemas bien concretos que afectaban a la vida y desarrollo de las poblaciones. No era por tanto una inquietud meramente moral, sino que en estricto rigor era una preocupación biopolítica3: "toda esta realidad... se refería a las condiciones de vida en que se desarrollaba nuestro pueblo, a saber; alcoholismo, altos índices de natalidad y mortalidad, analfabetismo (...)" (Cruzat y Tironi, 1987). Más aún, este relato de un "futuro mejor" que planteaba el debate de la "cuestión social", era abordado por los discursos de la época desde una perspectiva explícitamente de 'cuidado del cuerpo', que va más allá de la mera preocupación caritativa que habitualmente se acentúa en la literatura historiográfica sobre las "masas asalariadas" de la época (Godoy, 2008: 122). Los sujetos populares ya no solo serán, "objeto de prácticas correctivas y de la caridad, sino que la economía exigirá un nuevo discurso redentor que abogará por el cuidado del cuerpo del pueblo en función de consolidar una masa asalariada" (Becerra, 2009).

Las altas tasas de mortalidad significaban una pérdida económica para

\footnotetext{
${ }^{3}$ Para Edgardo Castro la biopolítica "aparece como una de las dos formas posibles de biopoder... y, en su sentido restringido, este es entendido como sinónimo de biopolítica. Este uso remite al "conjunto de mecanismos por los cuales lo que en la especie humana constituye sus trazos biológicos fundamentales puede ingresar dentro de la política" (Castro, 2004, p. $55)$.
} 
el país, muchos hombres quedaban excluidos de los procesos productivos ya sea por muerte o por una enfermedad mal tratada o por el consumo excesivo de alcohol y/o drogas.

Los llamados a "mejorar la raza" comenzaba a estar a la orden del día en los discursos de políticos, médicos, intelectuales y policías, entre otros ${ }^{4}, 10 s$ cuales tenían un fin único: otorgar homogeneidad a la población y así marchar juntos por la vía del progreso económico y la seguridad de la nación. El ideal era crear un pueblo sano y fuerte, trabajador/productivo e inteligente/educado a la altura de una nación joven en búsqueda de bienestar. Todos estaban llamados a formar parte activa de la construcción de la nación, excepto los "no aptos" de este relato: los alcohólicos (y luego, los toxicómanos), quienes representaban la degeneración biológica y decadencia moral de la sociedad. La construcción de esta categoría de anormales resulta por tanto muy funcional a lo que se requiere resguardar: un cuerpo social productivo a nivel de población. En palabras del doctor Carlos Fernández Peña, presidente de la Liga Nacional contra el Alcoholismo a comienzo de siglo XX:

hai pues que preservar la sociedad de estos ebrios incurables declarando su interdicción i secuestrándoles en los Asilos de Bebedores cuando todavía estén en estado de curabilidad, i no esperar a que estén al borde de hacerse incurables i hayan conducido a su familia a la ruina (Flade, 1902: 207).

Para esto "el Estado debe, pues, curar a los ébrios pobres, i así prevendría numerosos crímenes i evitaría los gastos que estos exigen" (Ibid.: 177).

La figura de los "no aptos" comienza a establecerse entonces a la par de las necesidades productivas del resto de la población, pero sigue un derrotero específico que lo volverá objeto privilegiado de saber científico. El primer paso del cuidado de los "no aptos" se comienza a institucionalizar con la creación de la Casa de Orates de Nuestra Señora de los Ángeles (1852), centro que dio acogida a los enajenados mentales provenientes de las cárceles y hospitales del país, principalmente de las clases populares. Es un

\footnotetext{
${ }^{4}$ Famosos son los trabajos de fines del siglo XIX y comienzos del siglo XX en los que se destaca esta idea: La Cuestión Social de Augusto Orrego Luco (1884), Raza Chilena de Nicolás Palacios (1904), y La Crisis Moral de la República de Enrique Mac-Iver (1900).
} 
acontecimiento relevante, pues significa que el Estado comienza a invertir recursos en tratar a los desadaptados asumiéndolos como un problema que afecta al conjunto de la población. Se deja atrás, la consideración de estas afecciones como excentricidades reservadas solo para privilegiados - aquellos que podían acceder a los tratamientos de la Casa de Locos de San Andrés (Lima, Perú), lugar donde la clase aristócrata chilena enviaba a sus familiares con problemas mentales.

El primer flagelo social identificado es el alcoholismo. En la época, se comienza a representar ya no como un asunto de marginales sino como un gran problema para el futuro de la nación. Así lo expresa Gerónimo Letelier Grez, quien, en su memoria de grado de licenciatura, señala que "la locura alcohólica en nuestro país ha alcanzado una proporción que espanta; más de la mitad de los ingresados [a la Casa de Orates] reconocen por causa de su enajenación los excesos en las bebidas alcohólicas" (Letelier, 1989: 7). Con casi una década de antelación, Manuel Segundo Beca en su "Contribución al Estudio de Enfermedades Mentales en Chile (1891)", señala que "son tres las grandes causas de enajenación que influyeron para la entrada de hombres al Manicomio en el año 1890 [...] 1. Abuso de bebidas alcohólicas; 2. Excesos venéreos y 3. Sentimientos, pesares, etc.” (Roa, 1974: 43). Así el sujeto alcohólico era configurado como un mal social que "constituye un peligro para la patria y el pueblo" (Flade, Op. cit.: 208), por lo cual debe ser internado y tratado tal como lo estipulaba la Ley de Alcoholes de 1902, particularmente en su artículo 152, donde se establecía que "como anexo a la Casa de Orates, deberá abrirse un establecimiento público con el nombre de Asilo de Temperancia".

Al contrario del alcoholismo, la toxicomanía por sustancias alcaloideas era todavía un problema menor para el Chile de fines del siglo XIX y principios del XX. Entre el año 1890 y 1897 ingresó a la Casa de Orates solo una persona en búsqueda de tratamiento, según el registro de ingresos por causas redactado por el antes citado Gerónimo Letelier Grez (Letelier, Op. cit.: 6). Sin embargo, el sujeto consumidor de sustancias narcóticas está consignado implícitamente en el Código Penal de 1874, la primera legislación 
que regulaba penalmente el expendio - no el consumo- de sustancias nocivas para la salud. Los artículos 313 y 314 del Código Penal versaban sobre los crímenes y simples delitos contra la salud pública, y otorgaban condenas de reclusión menor y pago de multas para los condenados del delito de proporcionar las sustancias.

Con el paso del tiempo y en pocos años este escenario cambiaría sustancialmente y la toxicomanía comienza a caracterizarse como un potencial riesgo de toda la población. Ya en 1927, Francisco Hernández, un profesional químico experto en alcaloides afirmaba categóricamente que "la Toxicomanía, vicio nuevo, que bien pudiéramos llamar flor malsana de la civilización, viene a sumarse hoy a los muchos males que aflijen a la humanidad" (Hernández, 1927: 169).

Por los mismos años, Víctor Grossi no tenía duda en señalar que:

Las toxicomanías, en sus versiones morfinómanas, opiómanas y cocainómanas], atacan la voluntad, son presas fáciles los pobres de carácter, los que no pueden resistir la contrariedad o el dolor, y así se reclutan hombres pudientes y distinguidos, el joven que pretende de moderno, la prostituta escasa de inteligencia y de cultura son los más fáciles campos de cultivo (Grossi, 1927: 46).

Las descripciones relativas a los alcaloides se asociaban con un discurso de degeneración y alienación muy propio de la psiquiatría de la época. El propio Hernández indicaba al respecto que:

por la puerta de la voluptuosidad, entran el opio, la morfina y la cocaína en los hogares del dilettanti, del sibarita, del hastiado, de la prostituta; en una palabra estos narcóticos predominan siempre como factores de degeneración entre esas gentes desequilibradas que buscan en un mundo irreal las impresiones que les niegan sus sentidos (Hernández, Op. cit.: 170).

Es importante destacar, que los primeros toxicómanos en Chile corresponden principalmente a personas de clases sociales más acomodadas ("hombres pudientes y distinguidos", "dilettanti"; el "sibarita"). Ello se debe fundamentalmente al poder adquisitivo de esas personas, o de sus familias, lo que les permitía acceso a sustancias como el opio, la morfina y la cocaína, que por su precio y distribución era aún de muy poco acceso para la población en 
general.

Sin embargo, rápidamente y en el curso de no más de treinta años, la toxicomanía se configura en los discursos centrales de la academia y el debate público como un flagelo que amenazaba con causar estragos en toda la población, aunque como ya indicamos los más afectados eran personas de clase alta.

A fines de la década de 1920, el llamado de la comunidad científica era uno solo: "la opiomanía constituye pues, un peligro social de la mayor gravedad y que importa conjurarlo por todos los medios" (Ibid.).

\section{EI discurso de "los efectos de las drogas" en los toxicómanos}

Con respecto a la representación de los efectos de las estupefacientes en los drogadictos difundida en los discursos de la época, es necesario constatar la mención de diversos estados (de goce y displacer) que tienen en común debilitar la voluntad del toxicómano e invalidar su vida productiva. En palabras del subcomisario de investigaciones Eduardo Pérez:

(1.0) Sensación muy agradables, con los que el paciente se siente seducido tanto por una ficticia satisfacción como por una nueva excitación; y 2.0) consecuencias muy martirizadoras, ya que el organismo de la persona luego es presa de horribles sufrimientos $/ .$. ) en este segundo grado, el individuo se presenta con palidez cadavérica, insensible, olvidado de su amor propio, sumergido en el cansancio y la tristeza. Un pobre harapo humano que, expuesto a la locura y el crimen, con sus condiciones morales y sexualmente impotente, va incitando a la relajación familiar y va dejando una descendencia afecta a su enajenación mental, con todo lo cual destruye para siempre la felicidad del hogar. En resumen, da realidad a los más graves trastornos sociales y económicos, ya que roba, mata, falsifica recetas, se prostituye o se dedica a formar prosélitos (Pérez, 1939: 56).

Ramón Iribarren nos señala, que en el caso particular de la toxicomanía por opio, "comienza por espíritu de imitación, después de escucharse relatos hermosísimos hechos por individuos ya enviciados que ponderan a grandes rangos y con lujo de detalles sus resultados, o bien por simple "snobismo" son víctimas de su abominable vicio" (Iribarren, Op. cit.: 90). Continúa argumentando que "tanto el opiómano y el morfinómano son seres humanos exentos del sentimiento de deber, de la responsabilidad y del honor; son 
individuos apáticos y cobardes" (Ibid.). Era bien sabido en la época que en las ciudades del norte existían "un buen número de fumaderos de opio y la coca está aniquilando a las poblaciones trabajadoras de la pampa" (Hernández, Op. cit.: 169), vendiéndose "libremente en cualquier despacho (...) por dedales, los chinos comercian entre ellos y las farmacias más rara vez intervienen en esta clase de comercio" (Grossi, Op. cit.: 46). Sin ir más lejos, en las calles de Santiago,

por los Boites de Bandera, por las casas de tolerancia y diversos sitios de diversión nocturna, se ha establecido que, los afectos al papelillo de cocaína, no viven horas de esparcimiento sin tener la certeza que luego podrán colocarse la inyección o aspirar la muerte del polvo (Segura, 1953: 50).

El inspector en retiro de la Policía Federal de Mendoza Emilio Ceriotto nos señala que el morfinómano presenta un "aspecto pálido, pupilas contraídas, adelgaza considerablemente, envejece rápido; la impotencia sexual se manifiesta al tiempo de constituir en él una verdadera obsesión (...) ese vicio repercute sensiblemente en los problemas hereditarios, ya que los descendientes de los morfinómanos resultan afectados de meningitis, tuberculosis, idiotez, etc." (Ceriotto, 1953: 10).

La cocaína por su parte, genera una, borrachera y como corolario, desencadena un delirio sensorial muy semejante a la mayoría de los delirios tóxicos (...) si agregamos que a esta locura está injertada sobre una narcosis que hace desaparecer los dolores físicos y morales, es fácil explicarse la extracción de la cocaína (Grunberg, Op. cit.: 19).

Los sujetos cocainómanos se vuelven "egoístas, susceptibles, intolerantes y agresivos, y como el alcohólico entran en conflicto con la sociedad" (Ibid.). Para los cocainómanos poco entrenados, el consumo de cocaína genera una euforia intensa y muy especial, caracterizada por "alegría profunda, sensación deliciosa del espíritu y el cuerpo, olvido de las penas (...) sentimiento de fuerza y de inteligencia" (Ibid.). Para Ceriotto, el cocainómano "es un individuo violento. Que siente constantes alucinaciones (...) llegan, incluso, a sentirse atacados por manía persecutoria" (Ceriotto, Op. cit.: 11). El morfinómano tiene una ventaja en comparación con el cocainómano, nos 
señala el autor, cual es que se puede curar "en cambio el cocainómano no; su voluntad queda relajada en tal forma que se hace imposible su regeneración" (Ibid.).

En las caracterizaciones antes indicadas, se mezcla un efecto degenerativo que afectaría al individuo y su familia. Pero al mismo tiempo, se mencionan los impactos socio-económicos que el consumo de los diferentes estupefacientes producen en el conjunto de la población. Debido a la escasa prevalencia de la figura del toxicómano en la población en general, el énfasis en los impactos socioeconómicos del conjunto de la sociedad (producidos por el consumo de estupefacientes) debe leerse como un recurso de normalización precisamente de la población sana. La figura del toxicómano es usada discursivamente, como sujeto a corregir, para gobernar las poblaciones (no toxicómanas) que están dentro de la norma, aludiendo al peligro de lo que ocurriría si estuviesen fuera de ella, a saber: "problemas hereditarios, ya que los descendientes de los morfinómanos resultan afectados de meningitis, tuberculosis, idiotez, etc" (Ceriotto, 1953: 10).

En otras palabras, tal y cual lo reconocen algunos comentaristas de la época: excluyendo la relación con la población sana, los morfinómanos y cocainómanos como categorías autónomas no constituyen ningún peligro para la sociedad, pues su existencia está reducida a las clases sociales altas:

nada harán contra las demás personas si no carecen de los excitantes que lo han sumido en el más tenebroso de los vicios. Sin embargo, hay que reconocer que son criminales en potencia, pronto a cruzar los umbrales del crimen si se les priva de las drogas que necesitan para subsistir con apariencias de seres normales" (Roget, 1946: 46).

Incluso, considerando exclusivamente sus efectos particulares en un toxicómano "ideal" (esto es, que no devenga en generalizable para el resto de la población), los especialistas de la época retratan de manera halagadora el efecto que produce el "haschis",

la sensación más divina del mundo. Bajo la influencia de la droga, se vive una región de ensueños, cuyos colores no son sombríos como el opio, o neutrales y desordenados como el cloral, o enervantes como los de la cocaína: El firmamento 
interior del consumidor de haschis se enciende en un deslumbramiento de bellísimos colores (Hermann, 1945: 85).

Al cabo de pocos minutos de haber consumo "haschis", se observa "una especial excitación y verborrea, así como accesos de risa incontenible, que constituye la primera fase de embriaguez" (Fernández y González, 1953: 474). En la fase máxima de embriaguez presentan obediencia automática, aunque son capaces de volver rápidamente a la normalidad, quedando solamente con una imperiosa sensación de hambre.

Estas caracterizaciones alcanzan niveles de idealización excelsa en la comparación entre los efectos de la morfina y la cocaína que nos plantea Alfredo Grunberg:

el morfinismo tiende a realizar el ideal budista: el nirvana, la retracción voluptuosa del ser sobre sí mismo; el cocainismo tiende más hacia el ideal nietzscheano: "la voluntad de poder"; expansión enérgica y triunfante de la personalidad en el mundo exterior (Grunberg, Op. cit.: 20).

Es debido a esta relativa idealización de los efectos de los estupefacientes que la función normalizadora del toxicómano, como "sujeto a corregir", en relación a la población productiva "sana", tiende a debilitarse. Se necesitó del encadenamiento con la figura del traficante, como veremos luego, lo que coincide con la preocupación pública que en adelante se va a centrar en el tráfico de drogas. Para observar este tránsito es necesario primero analizar las estrategia de corrección usadas contra los toxicómanos.

\section{Las estrategias de combate en contra la nueva amenaza: los toxicómanos}

La primera estrategia en contra del desarrollo de la toxicomanía fue la suscripción, por parte de Chile, de la Convención Internacional del Opio de 1912. Se trató del primer paso en la constitución de una normativa multilateral que buscaba controlar el comercio, distribución y uso de opio, morfina y cocaína a nivel mundial. Es así que el artículo 9 de dicha Convención señala:

las Potencias contratantes dictarán leyes o reglamentos sobre farmacia, de modo de limitar la fabricación, venta y empleo de la morfina, cocaína y sus respectivas 
sales, solo a los usos médicos y lejítimos, salvo que la materia se encuentre ya reglamentada por leyes y reglamentos existentes. Cooperarían entre ellas para impedir el uso de esas drogas para cualquier otro objeto.

En 1915 Adolfo Meyer presentaba un intento para reglamentar la práctica de las farmacias, boticas y droguerías. En dicho estudio señalaba su preocupación por la gran cantidad de toxicómanos que estaban surgiendo en Chile:

Es ya mui urjente la necesidad de poner término al vicio de la morfina i de la cocaína, ya tan vulgarizados en Chile como el alcoholismo, que es ruina de muchas familias. Actualmente, se vende la morfina, sobre todo en tabletas, como el pan, i mas todavía, se despacha a niños chicos, por la vergüenza que manifiestan tener ya los consumidores (Meyer, 1915: 34).

El mismo Meyer nos señala la emergencia del sujeto toxicómano y la peligrosidad del consumo de drogas para la sociedad:

los envenenamientos se cuentan por centenares todos los años, i la venta de morfina, cocaina i otros medicamentos para el vicio i la corrupción se ha propagado ya de una manera alarmante. Conocidas de todos es a este respecto la campaña activa e intelijente, que ha emprendido el señor Intendente de Santiago, para perseguir el funesto vicio de la morfinomanía (Ibid.: 5).

En ese entonces ya era todo un hecho que en los discursos públicos, la toxicomanía había llegado al país para quedarse y hacer compañía al alcoholismo, como objeto central de regulación biopolítica. La toxicomanía ha dejado de ser una dolencia individual para ser considerada una condición que afecta al conjunto de la población. Un comentarista de la época (1927) señalaba resignado que:

por cualquiera sea las razones que la filosofía, la biología y el psicoanálisis nos diga sobre las causas de las toxicomanías, un hecho, dice Legrain, domina la historia de los venenos de la inteligencia y es que el veneno ha dejado de ser el caso clínico de un desgraciado enfermo, para ir extendiéndose y abarcando numerosos grupos de hombres, hasta llegar a afectar progresivamente la humanidad entera (Grossi, Op. cit.: 46).

El mismo autor continúa afirmando que, “el alcohol, el tabaco, el opio, la cocaína, tienen ya no solo la etiología y patología individual, sino que 
revelan un carácter colectivo con caracteres físicos y morales que abarcan una ciudad, un país o un continente" (Ibid.).

En la constitución de la toxicomanía como objeto de regulación biopolítica, se advierte una trasmutación del discurso científico práctico en relación a las llamadas "drogas heroicas". Esto es, las utilizadas por la ciencia de la época previa a la década del 20 del siglo pasado principalmente para aliviar dolores. Y como tal, no eran consideradas hasta entonces como agentes adictivos que atentaban contra la salud de la población. Recordemos que la sintetización de la morfina a gran escala y su uso médico y farmacéutico ocurrió recién en 1827 y en el caso de la cocaína en 1878. La morfina en un principio fue sintetizada como analgésico y como un fármaco para combatir la adicción del alcohol y el opio. La cocaína es considerada como una droga moderna. Recién en 1878 W. H. Bentley "tuvo la funesta idea de tratar la morfinomanía sustituyendo la morfina por cocaína” (Grunberg, 1929: 18), lo que en un principio tuvo alentadores resultados en su empleo para la cirugía, pero a la larga provocó una enfermedad para "vencer" otra. Hasta las primeras décadas del siglo XX, en Chile dichos medicamentos aún eran vistos como una revolución en las ciencias médicas y farmacéuticas, como indica Enrique Merck, recordando un dicho que era asumido por muchos en la medicina chilena de entonces: "ese medicamento [la morfina] cuya importancia todavía en el siglo XX un célebre clínico alemán caracterizó con las siguientes palabras: Sin morfina no quisiera ser médico" (Merck, 1927: 122).

Con el paso del tiempo, el discurso médico y farmacológico chileno e internacional se uniforma en la advertencia de la peligrosidad de dichas sustancias. Para ello fue central la observación relativa a las fuertes adicciones provocadas en los pacientes/consumidores. Es así como en una publicación del Boletín Farmacéutico de 1928 se hace referencia a la peligrosidad de los narcóticos, de los cuales "se sabe que producen fenómenos de intoxicación cuando son tomados en dosis fuertes, por lo que esta clase de substancias se han empleados bastante, no sólo en las novelas sino también en la realidad, para intentos de suicidios" (Boletín Farmacéutico, 1928: 251).

Sin embargo, aún el énfasis era que las sustancias debidamente 
suministradas no ocasionan graves problemas a la salud de la población, salvo en casos de excesos de consumo de estos. Se buscaba con ello mantener el gobierno de los estupefacientes bajo control exclusivamente de la disciplina médica que en Chile mantenía un poder gremial muy significativo en estas materias. Así, en la literatura revisada, el control del expendio de estupefacientes en primera instancia (y tal como lo señaló Meyer con anterioridad) se suministraba en boticas y farmacias que al no tener una reglamentación referente a la materia, el abastecimiento de drogas quedaba bajo criterio del farmacéutico de turno. En ese entonces, la cadena del consumo de alcaloides estaba compuesta por el médico, el paciente/consumidor y el farmacéutico. Los médicos eran los encargados de recetar sustancias alcaloides a los pacientes. El paciente/ consumidor se dirigía a la botica más cercana y mediante una receta médica obtenía el fármaco elaborado por el farmacéutico (siguiendo las directrices estipulada en la prescripción).

En resumen, la producción y comercialización de drogas estaban en manos del cuerpo médico y de los farmacéuticos, y como tal, todos los habitantes del país podían en principio acceder al consumo de estas sustancias simplemente teniendo una prescripción emitidas por facultativos médicos y luego acudiendo a la botica de turno - aunque en la práctica los que accedían era la población de estrato social alto. De esta manera, sostiene Ramón Iribarren:

tanto la morfina como el opio, en un principio fue empleado en Chile por la ciencia médica, como calmante en ciertas dolencias, pero más tarde los mismos médicos hubieron de resistirse a su empleo por el funesto vicio que de tales drogas se estaba haciendo (Iribarren, 1942: 90).

En palabras de un comentarista de la época, "antiguamente era fácil eludir la acción y responsabilidad penal por venta y suministro de drogas venenosas, toda vez que no existía un Código Sanitario vigente ni había reglamentación que sancionara esta clase de delitos" (Ibid.).

El debilitamiento de este modelo de control médico de los estupefacientes se produce desde el interior de la propia disciplina médica. En efecto, algunos 
farmacéuticos y médicos comenzaron a expresar su preocupación ante los vacíos legales de esta cadena de distribución, debido a que, con el paso del tiempo, se hacía más habitual la falsificación o robo de recetas para comprar estupefacientes. La revista La Farmacia Chilena consignaba que "los autores de dichas falsificaciones no han respetado ni el nombre de algunos facultativos fallecidos. Eso bastará a nuestros lectores para juzgar la desfachatez que han gastado algunos caballeritos morfinómanos" (La Farmacia Chilena, 1927a: 144). En otros casos, algunos médicos las otorgaban a cambio de dinero, o bien se conseguían del mal actuar de farmacéuticos que proporcionan las sustancias sin ninguna contemplación sobre la salud de la persona. La Farmacia Chilena señalaba la práctica de algunos farmacéuticos inescrupulosos: "A una farmacia de Alameda de las delicias la sorprendieron los inspectores sanitarios en el tráfico de narcóticos y pudieron comprobar que dos empleados del mismo establecimiento eran morfinómanos" (Ibid.: 162).

La respuesta vino desde el propio gremio y para intentar contrarrestar las malas prácticas del cuerpo farmacéutico del país, se procedió a confeccionar un Código de Moral Farmacéutica, que en su artículo 12 estipulaba que "todo profesional debe contribuir a vigilar la venta de narcóticos, ya que su abuso significa solo la explotación del vicio" (Donoso, 1927: 54). Se asientan así los marcos jurídicos y prácticas regulatorias que trasladaban el eje de gubernamentalidad desde el toxicómano, como sujeto a corregir clásico perteneciente a las clases pudientes, a una nueva figura de anormalidad: el traficante.

\section{Del Toxicómano al traficante}

El dispositivo de control centrado exclusivamente en el gobierno de los toxicómanos comienza a revelarse como muy poco efectivo. Ello se debe a la incapacidad creciente de dicho dispositivo de controlar una realidad que pasa de estar remitida sólo a la figura de los toxicómanos, esto es, "sujetos a corregir" pertenecientes a las clases pudientes, a un fenómeno más complejo, a saber: el incipiente negocio internacional de tráfico ilícito de alcaloides, al 
que Chile pronto se vería muy expuesto.

En la época (1927), aún se creía que con las características geográficas del país, su "supuesto" aislamiento natural producido por la Cordillera de los Andes y los accidentes geográficos, Chile no estaba expuesto a éstos males, que en palabras del farmacéutico Francisco Hernández, "considerábamos exóticos, pero a medida que los vamos estudiando, iremos viendo que han ido tomando más y más cuerpo" (Grossi, Op. cit.: 46).

El mismo comentarista nos señala que "debe atribuirse al enorme desarrollo que va tomando en el mundo entero la manía del opio, la de la morfina, la cocaína y otras diversas sustancias de propiedades narcóticas" (Hernández, Op. cit.: 169) y Chile no estaba exento de este "contagio universal y empieza ya a sufrir las consecuencias de la funesta plaga" (Ibid.).

El tráfico de estupefacientes fue entonces explicado como una derivación del "intercambio comercial entre los diversos países, tan fácil hoy en día con los nuevos elementos del progreso, que ha logrado poner en íntimo contacto a las civilizaciones infiltrándose unas a otras sus vicios y sus tendencias" (Ibid.).

De ahí entonces, que la reacción inicial fuese el control de "extranjeros indeseables" - principalmente chinos (opio), bolivianos y peruanos (cocaína) - a los que se les atribuía el aumento del consumo descontrolado de estupefacientes en la población chilena. Su expresión institucional se dio en la denominada Ley de Residencia de 1918, la cual en su artículo 2 señalaba que,

\footnotetext{
Se prohíbe entrar al país a los estranjeros que practican o enseñan la alteración del órden social o político por medio de la violencia. Tampoco se permitirá el avecindamiento de los que de cualquier modo propagan doctrinas incompatibles con la unidad o individualidad de la Nación; de los que provocan manifestaciones contrarias al órden establecido, i de los que se dedican a tráficos ilícitos que pugnan con las buenas costumbres o el órden público.
}

Los extranjeros pasaron a estar en el ojo de las autoridades. En la revista La Farmacia Chilena se exponen diversas acciones de los inspectores de Sanidad donde se ven inmiscuidos extranjeros de varias nacionalidades, como cuando el "señor Oscar Rodríguez, Director General de Sanidad, 
hizo aprehender al ciudadano yugoeslavo Nicolás Yudresich, porque había intentado sobornarlo con el objeto de conseguir un permiso para internar mayores cantidades de coca" (La Farmacia Chilena, 1927b: 36). Afirmando este punto, el doctor Víctor Grossi nos señala que "cuando se piden drogas con la debida discreción pronto se llega al conocimiento de un cosmopolitismo en que actúan chinos, rusos, ingleses, alemanes y nacionales como difundidores de las drogas, pero las víctimas son sobre todo nuestras" (Grossi, Op. cit.: 46). El mismo autor sentencia que en el país "se estima prudentemente que el $80 \%$ de los chinos usan, trafican o se dedican al tráfico de opio" (Ibid.).

Con ello, la toxicomanía sale del territorio exclusivamente del control médico y se asume ahora derechamente como un problema delincuencial a perseguir penalmente. Ello ocurre no porque la afectación de la población a los estupefacientes fuese significativa, sino porque la vinculación causal del "descontrol" se da con la migración indeseable, lo que convierte a los toxicómanos en objeto de regulaciones más complejas. Esto no significa que este proceso haya sido pensado íntegra y coherentemente desde un comienzo. Por ejemplo, para la década del 20 del siglo pasado, el control de las drogas estaba en manos de la Inspección de boticas. Una institución nueva pero compuesta por dos modestos funcionarios públicos que tenían "la ridícula misión de vigilar y controlar el comercio y el ejercicio de la profesión farmacéutica en todo el territorio de la Republica" (Latorre, 1928: 48), la cual fracasa debido precisamente a su falta de personal y su poca efectividad. A su vez, el Código Sanitario de 1918 no contaba con infracciones para controlar el problema de las drogas en Chile, el que aún seguía solo penalizado por los artículos 313 y 314 del Código Civil de 1874.

Incluso más elocuente de esta incipiente regulación es que en 1927 el Director de la recién creada institución de Carabineros de Chile, Aníbal Parada, pedía al gobierno central que "1. El monopolio del Estado para importación y venta de alcaloides, y 2. Severas sanciones para quienes expendan o usen ilícitamente" (Grossi, Op. cit.: 91).

A su vez, el doctor Víctor Grossi en su estudio referente a Los venenos sociales en Chile, resumía lo que a la época (1927) era la visión de la comunidad 
científica al respecto:

"1. La difusión del consumo y tráfico de narcóticos, constituyen un grave peligro social.

2. El uso vedado de narcóticos es un acto criminal, que equivale a un suicidio y afecta a la decencia, al individuo y al Estado. Las toxicomanías degeneran la raza, provocan la locura y favorecen el crimen.

3. El consumo médico de los narcóticos es un problema sanitario. La contravención o tráfico ilícito para satisfacer la criminal afición a las drogas, es un problema policial y debe caer en las sanciones del Código Penal.

4. El poder legislativo debe dictar medidas severas para reprimir el consumo de narcóticos que empieza a causar graves daños en nuestro país.

5. La Sociedad Médica acuerda propiciar la educación de nuestra juventud sobre bases morales más amplias, señalando los graves peligros que por el consumo de estas drogas le amenaza.

6. Nuestro país adhirió al llamado Congreso de la Haya, que es Ley de la República. El Código Sanitario establece penas insignificantes y el decomiso, reglamentación irrisoria para combatir el uso ilícito de drogas. Sólo una represión enérgica se ha establecido en las conferencias internacionales puede acabar con la impunidad que alienta el clandestinaje.

7. Por lo que hay necesidad de tener un personal inteligente y avezado que se dedique exclusivamente a combatir a estos criminales expertos que ejercen el clandestinaje" (Ibid.: 75).

La respuesta a la crítica devastadora del doctor Grossi llegó con el nuevo Código Sanitario (1931), el cual, en esta ocasión, sí consignaba infracciones para el problema de las drogas. Así el artículo 244 nos dice,

que toda infracción relacionada con la fabricación, importación y expendio de drogas narcóticas, estupefacientes y sustancias capaces de producir hábitos nocivos, así como las infracciones relativas a la adulteración, falsificación o contaminación de cualquier otro producto mencionado en esta ley, serán castigadas, además, con el comiso y pérdida de tales sustancias o productos y, si se estimare procedente, con la clausura del local en que se elaboren o expendan, hasta que autorice su reapertura el Director General de Sanidad. 
En la década del 1930, en la denominada cadena de consumo de alcaloides, ya es claro este nuevo factor que comienza a ser objeto de regulación, a saber: el tráfico ilegal de estupefacientes. Los comentaristas de la época comienzan a dejar registro de estas nuevas regulaciones al señalar por ejemplo que él,

Código Sanitario y los Reglamentos vigentes de la Inspección y Reglamentación sobre ventas de drogas y específicos, contienen severas disposiciones sobre el expendio de drogas consideradas venenosas y establecen la culpa penal a que se hacen acreedores los comerciantes y dueños de farmacias que vulneran dicha reglamentación (Barros, 1945: 31).

Con la entrada en vigencia de diversas normas para reglamentar el expendio y penalizar el tráfico de drogas, el acceso y consumo de estas sustancias es cada vez más restringido y solo "se observa en individuos de la burguesía y la aristocracia" (Toro, 1942: 42). La focalización de la figura del toxicómano en las clases altas era una característica que ya se observaba en las últimas décadas del siglo XIX, como antes vimos. No obstante, la diferencia está en que ahora, con las nuevas reglamentaciones del consumo y fabricación de alcaloides, el acceso regulado a los estupefacientes se hace aún más restringido y en la práctica ello delimita un tipo de consumidor que proviene casi exclusivamente de la burguesía y la aristocracia chilena, esto es, que cuenta con el suficiente poder social y económico para acceder a los alcaloides.

Para Luis Toro, "es rarísimo un proletariado cocainómano o morfinómano, generalmente cuando se produce, es un toxicómano de las otras clases sociales el que no solo lo inicia sino le mantiene el hábito" (Ibid.). El autor reafirma su punto señalando que,

los individuos de clase alta, y especialmente, de la aristocracia, son los cultores habituales del alcaloidismo, porque en ellos, el factor individual, la falta de voluntad, sensación de irresponsabilidad y miedo a la vida, toma ciertas características intelectualizadas, imaginativas, cuya regulación concuerda mejor con el tipo de excitación, o falta de vitalidad que dan los alcaloides (Ibid.). 
Sin embargo, esta época "aristocrática" de los toxicómanos estaba pronta a llegar a su fin con la emergencia de una nueva figura fuera de la norma: el delincuente traficante.

Se produce entonces una nueva construcción discursiva dentro de los dispositivos de gubernamentalidad de los estupefacientes que circunscribe a la figura del toxicómano como un sujeto excéntrico de clase alta, pero en algún sentido vinculada (mediante el consumo) con este nuevo sujeto "traficante" que aparece como la nueva amenaza a controlar.

En 1942 la situación de estos dos sujetos a gobernar, el toxicómano y el traficante, era aún bastante indiferenciada. Cada vez es más difícil la adquisición de estupefacientes, debido a las diversas reglamentaciones que han puesto freno al expendio, tráfico y consumo, lo que produjo que su oferta disminuyera, aumentando el precio y dificultando el acceso. Ello estimula a su vez el tráfico ilegal de estupefacientes. En palabras del policía Luis Toro:

los alcaloides son sustancias caras y su adquisición habitual es clandestina, lo que necesita una organización, una compra y venta, cuya ilegalidad la hace más cara aún. Sólo gente con cierta solvencia económica puede, por lo menos al iniciar el hábito, ingresar a la cofradía del alcaloidismo (Ibid.).

Para la década del 50, ocurren dos hitos importantes para esta genealogía. El primero fue que las autoridades sanitarias y policiales ya habían conjugado sus fuerzas para combatir el tráfico ilícito de estupefacientes. Una de sus primeras pesquisas fue contra un grupo de ciudadanos chinos que se dedicaban al tráfico de opio en la capital. Esto da origen, una década después, a la Brigada de Represión del Tráfico de Estupefacientes y Juegos de Azar (BEJA). El segundo hito, fue el establecimiento de la Ley 11.625 de Estados Antisociales, la cual en su artículo $1^{\circ}$ consignaba a la figura del toxicómano al mismo nivel que los alcohólicos, vagabundos, homosexuales y ladrones, entre otros. Esto es, se consagra la subjetividad toxicómana como un sujeto a corregir socialmente y al traficante como un sujeto a castigar penalmente. La diferencia seguía asentada en su extracto social. El toxicómano aún mantiene lo resabios de su origen vinculados a las clases sociales más pudientes de 
nuestro país y, por tanto, objeto de "control y gobierno" a fin de ajustarlos a la norma social. Los traficantes en cambio, son desde el comienzo asociados a las clases sociales más bajas de la población, incluso a la población migrante indeseada ("los chinos", por ejemplo), y sobre ellos se ejerce directamente el castigo penal. Podemos avizorar aquí, el origen de la estigmatización social del traficante (la nueva figura más amenazante para el control social de las vidas productivas), la que devendrá en una criminalización activa del micro tráfico (que se extiende hasta nuestros días), asociado precisamente a las clase bajas, pero una relativa poco eficiente persecución del gran traficante, asociado más al toxicómano clásico de origen social acaudalado.

\section{Conclusiones}

La figura del toxicómano no es pacífica ni menos neutral en su cientificidad. Resulta de una producción discursiva y no discursiva que se inscribe dentro de un dispositivo de poder biopolítico desplegado discontinuamente en Chile en el último cuarto del siglo XIX y hasta mediados del siglo XX al menos. Incluso al interior de ese dispositivo, la caracterizaciones del toxicómano como "sujeto a corregir" varían y va adquiriendo nuevos énfasis en la medida que su función reguladora se establece como central, a saber: la constitución un patrón de anormalidad de cara al gobierno de la población sana y por tanto productiva. No es tanto la "verdad científica" sobre el toxicómano lo que va precisando los contornos de esta subjetividad sino su funcionalidad a un dispositivo mayor de control. En este sentido es que la producción discursiva $\mathrm{y}$, a la postre, normativa del toxicómano no tiene una primera influencia masiva como lo tiene el discurso de la "cuestión social" a comienzos del siglo $\mathrm{XX}$, dado que su impacto es acotado tanto en términos intelectuales como socio-económicos, sin embargo será una figura que a la larga conformará un mecanismo de control y disciplinamiento social más fuerte y mucho más extendido, a saber la figura del "traficante criminal”.

Este tránsito que va desde el "toxicómano" hacia la del "traficante", puede ser representado con el lenguaje de Michel Foucault como el tránsito que va desde un "sujeto a corregir", es decir de un sujeto social cuya anormalidad 
depende de los dispositivos normativos que lo constituyen, hacia un "sujeto disciplinado" más tradicional, entendido como un cuerpo dócil que será oprimido por instituciones de vigilancia y castigo como es la cárcel.

De esta manera podemos constatar que, efectivamente, existe una constitución normativa que dará lugar al "toxicómano" como una figura relevante dentro de la discusión sobre el control social en Chile durante fines del siglo XIX y la primera mitad del XX, y que esta constitución de la figura del toxicómano derivará en lo que luego conoceremos de manera masiva como el "traficante", que será abordado mediante una operación constitutiva del sujeto más tradicional apoyada en los dispositivos de control y disciplinamiento penales.

La figura del toxicómano, por tanto, será progresivamente abandonada dado que se convertirá en una subjetividad cuya funcionalidad enfocada al control social será más débil que la que puede proporcionar la figura del traficante, lo cual se manifiesta de manera específica en que el control del traficante, a diferencia del toxicómano, será regulada por las leyes penales de aplicación general en el país. Así, quedará pendiente la revisión del contexto de producción del traficante como una nueva subjetividad y mecanismo de producción de subjetividades que operará de manera masiva durante la segunda parte del siglo XX.

\section{Referencias}

Barros, L. (1945). La culpa penal de la venta de drogas venenosas. En Revista de Criminología y Policía Científica. 7 (69). Disponible en la Hemeroteca de la Biblioteca Nacional de Chile.

Becerra, M. (2009). De psicosis tóxica a predisposición mórbida: Emergencia de la figura del toxicómano en Chile: 1872 - 1954. Santiago, Chile: Red de investigadores de biopolítica. 
Boletín Farmacéutico (1928). Crónica científica. Boletín Farmacéutico 1 (8). Disponible en la Hemeroteca de la Biblioteca Nacional de Chile.

Castro, E. (2004). El vocabulario de Michel Foucault. Buenos Aires, Argentina: Universidad Nacional de Quilmes.

Ceriotto, E. (1953). La delincuencia en la toxicomanía. Revista de Criminología y Policía Científica 13 (167). Disponible en la Hemeroteca de la Biblioteca Nacional de Chile.

Cruzat, X. y Tironi, A. (1987). El Pensamiento frente a la Cuestión Social en Chile. Buenos Aires, Argentina: Nuestra América Ediciones.

Donoso, R. (1927). Ética de la profesión farmacéutica. La Farmacia Chilena 1 (3). Disponible en la Hemeroteca de la Biblioteca Nacional de Chile.

Flade, E. (1902). La Cuestión del Alcohol. La marcha de la temperancia en los diferentes países. En Revista Farmacéutica Chilena 1 (7). Disponible en la Hemeroteca de la Biblioteca Nacional de Chile.

Fernández, A. y González, R. (1953). El club de los fumadores de Haschisch en el Marruecos español. En La Farmacia Chilena 23 (10). Disponible en la Hemeroteca de la Biblioteca Nacional de Chile.

Godoy, E. (2008). El discurso moral de los anarquistas chilenos en torno al alcohol a comienzos del siglo XX. Osorno, Chile: Editorial Universidad de los Lagos.

Grossi, V. (1927). Los Venenos Sociales en Chile. En La Farmacia Chilena 1 (4). Disponible en la Hemeroteca de la Biblioteca Nacional de Chile. 
Grunberg, A. (1929). Cocainomanía y Cocainismo. En Boletín Farmacéutico 3 (8-9). Disponible en la Hemeroteca de la Biblioteca Nacional de Chile.

Hermann, B. (1945). El haschis, aroma del Paraíso. (En pleno New York se cultiva la terrible Planta Narcótica). En Revista de Criminología y Policía Científica 6 (75). Disponible en la Hemeroteca de la Biblioteca Nacional de Chile.

Hernández, F. (1927). Toxicomanías. En La Farmacia Chilena 1 (12). Disponible en la Hemeroteca de la Biblioteca Nacional de Chile.

Iribarren, R. (1942). El Opio. En Revista de Criminología y Policía Científica. 4 (44). Disponible en la Hemeroteca de la Biblioteca Nacional de Chile.

Latorre, L. (1928). La inspección de alimentos y drogas. La Farmacia Chilena. 2 (3). Disponible en la Hemeroteca de la Biblioteca Nacional.

La Farmacia Chilena (1927a). Higiene. Falsificación de recetas. La Farmacia Chilena 1 (10). Disponible en la Hemeroteca de la Biblioteca Nacional de Chile.

La Farmacia Chilena (1927b). Vida Farmacéutica (uso de la coca). La Farmacia Chilena 1 (3). Disponible en la Hemeroteca de la Biblioteca Nacional de Chile.

Letelier, G. (1898) Contribución al estudio de las enfermedades mentales en Chile. Memoria de prueba para optar al grado de licenciado en la Facultad de Medicina i Farmacia. Museo nacional de la Historia de la Medicina. Universidad de Chile. Santiago, Chile. 
Merck, E. (1927). 100 años de fabricación de morfina. La Farmacia Chilena. 1 (9). Disponible en la Hemeroteca de la Biblioteca Nacional de Chile.

Meyer, A. (1915). Estudio sobre un reglamento para boticas i droguerías. Memoria de prueba para optar al título de Farmacéutico en la Universidad de Chile. Santiago de Chile.

Miranda, M. y Girón Sierra, Á. (eds.) (2009). Cuerpo, Biopolítica y Control Social. Buenos Aires, Argentina: Siglo XXI.

Miranda, M. y Vallejo, G. (Eds.) (2012). Una Historia de la Eugenesia. Buenos Aires, Argentina: Editorial Biblos.

Pérez, E. (1939). Breve estudio sobre los estupefacientes. En Revista de Criminología y Policía Cientifica 1 (14) Disponible en la Hemeroteca de la Biblioteca Nacional de Chile.

Roa, A. (1974). Demonio y psiquiatría. Aparición de la conciencia científica en Chile. Santiago, Chile: Editorial Andrés Bello.

Roget, C. (1946). Morfina, cocaína, alcoholismo y crimen. Revista de Criminología y Policía Cientifica 7 (90). Disponible en la Hemeroteca de la Biblioteca Nacional de Chile.

Segura, G. (1953). El opio. En Revista de Criminología y Policía Cientifica 13 (168). Disponible en la hemeroteca de la Biblioteca Nacional de Chile.

Sierra Castillo, M. (Ed.) (2010). Reflexiones sobre la Gobernabilidad del Individuo. Madrid, España: S\&S Editores. 
Toro, L. (1942). Toxicomanía. En Revista de Criminología y Policía Cientifica 4 (44). Disponible en la Hemeroteca de la Biblioteca Nacional de Chile.

Vásquez, A. (2012). "Los anormales". Una genealogía de lo monstruoso. Apuntes para una historiografía de la locura. Nómadas, revista crítica de Ciencias Sociales y Jurídicas 34 (2). 
